\title{
Espai Grafica
}

Grafica space

\section{\#EDITORIAL. volumen 1.2}

El tema principal d'aquesta editorial es escriure una nova pàgina del trajecte de la revista i del projecte que representa grafica. Hem titulat l'editorial com "Espai grafica» amb la intencionalitat de fer un símil amb el què representa l'espai de color. De la mateixa manera que l'espai color queda definit per els colors perifèrics que el delimiten i el constitueixen, l'espai grafica queda delimitat per les idees que en el projecte editorial de la revista queden reflectides o contemplades. En aquest sentit, en els darrers mesos des de la darrera edició hem orientat la tasca d'afirmació de la revista com a medi pel món gràfic en ampliar les vinculacions acadèmiques i científiques que donin solvència al projecte editorial. Això ha permès augmentar els membres de les comissions i derivadament, augmentar els punts de vista i les preocupacions, que en aquest sentit, poden ser referents per grafica.

Unes de les primeres preocupacions i implicacions que volem posar a debat és què és la investigació en disseny gràfic? La pregunta sembla ingènua però en el fons no en té rés. Si en les línies argumentaries que donen sentit a la revista grafica eren les múltiples perspectives que sobre aquesta activitat es tenen; és normal que la resposta a la pregunta formulada pot tenir més d'una resposta. Certament que l'orientació de la revista està condicionada o auto condicionada voluntàriament, pels criteris d'avaluació de revistes científiques. No obstant, no podem menystenir la reflexió conceptual que els estudiosos fan a través dels seus treballs. A més, donat l'interés de la revista en ser útil als diversos agents, científics, acadèmics, estudiants i professionals fa obligat a poder donar sortida a les diverses necessitats i obligacions que adquirim.

Per aquesta raó, grafica va sortir per primer cop amb un format i seccions que permeten ser sensible a qualsevol perspectiva que sobre el disseny es vulgui posar en comí. La secció d'Expertia per a consagrats autors, que com a experts, poden donar un punt de vista reflexiu i amb molta utilitat a qui ens trobem a 
mig camí o iniciant-lo. En aquest sentit, escoltar i saber escoltar el què estudiosos que han fet el camí molt abans que els altres, són capaços d'explicar-nos, ens ha de donar la capacitat d'adquirir una solvència com a àmbit de coneixement que sovint reclamem i no som capaços de tenir. Per la seva part, la secció d'articles d'investigació, centre estratègic de la revista, ha de ser el motor de divulgació científica i acadèmica que ens permeti evidenciar l'hegemonia del disseny i del disseny gràfic en moltes de les activitats socials. A més articles i més orientats als cànons de referència científica internacional més seguretat de que estarem fent bé les coses. Això significarà que tindrem un espai, un espai grafica, de referència per estudiants, professionals, acadèmics i científics, qüestió aquesta que no ha estat mai plantejada amb tanta profunditat i amplitud amb anterioritat. En aquest sentit, sovint, les revistes dedicades al món gràfic i del disseny s'han orientat més a qüestions divulgatives, especulatives i de marcació de tendències formals. No és aquesta la idea editorial de grafica. Volem estar al servei de la construcció d'un coneixement sobre del què es podrà seguir construint coneixement científic. Així doncs, la secció d'articles és per grafica, l'eina principal i única per la que grafica obtindrà l'excel·lència futura.

Però no podem fer una revista únicament amb articles científics, si més no ara per ara. Per això, l'Expertia, i per això també, les ressenyes. Aquesta secció ha de donar sortida a qualsevol idea d'aportació que no pugui entrar en els criteris, estrictes criteris científics de grafica, que són allunyats als tradicionals criteris divulgatius de les revistes sobre disseny.

A les ressenyes tenen cabuda qualsevol escrit que parli sobre disseny i des de les més amplis perspectives possibles. Estudis de cas, Anàlisis crítics, Cròniques, Reportatges tenen en la secció de Ressenyes, un espai perfecte per desenvolupar els seus pensaments. Especialment aquesta secció ha estat pensada per fer notes de premsa o breus descripcions de treballs científics, treballs finals de grau o màster, o de qualsevol treball que estudiants puguin haver realitzat en els seus estudis i que tinguin un interès concret en ser compartits. Sovint, aquest treballs queden publicats en revistes que el temps les fan caduques. El fet que grafica sigui editada online fa que pugui ser indexada, referenciada i trobada en la xarxa per sempre més. A banda de l'interès dels autors, aquí també volem mostrar l'interès per la comunitat donat que sovint no es coneix el què fan estudiosos del tema siguin aquests propers o allunyats.

Així doncs, volem fer partícips als nostre lectors que sabem el què busquem i sabem les dificultats que 
tenim al davant però també som conscients dels motius que ens impulsen. Les dificultats inicials que tota publicació com grafica tenen les convertim en els motius essencials per seguir treballant; de la necessitat de trobar el to científic i la utilitat requerida per grafica, en fem l'objectiu a assolir; de la necessitat d'implicar a tots els estudiosos d'arreu del món, i en especial de llatinoamèrica, en fem l'estratègica que ha de donar solvència; $i$, finalment, de la obligació de ser un servei als públics interessats en el disseny gràfic, en fem una raó d'existir. Si a aquestes idees n'afegim la necessitat de aconseguir, en un temps raonable, la indexació de grafica com a revista científica, trobarem l'explicació al treball que estem realitzant.

Treball per tant, que es pot visualitzar en la construcció d'un espai grafica on tothom ha de tenir cabuda i un espai on tothom ha de sentir-se com a propi i referencial. Tant el Col-legi Oficial de Disseny Gràfic de Catalunya com a agent emulsionant, com les Escoles de disseny, Universitats, professionals i acadèmics, d'àmbits lingüístics diferents, o de d'àmbits geogràfics nacionals o internacional diferents, són cridats a motivar, impulsar i difondre l'ús de grafica com a referent pel desenvolupament de grafica.

En el cas de la segona edició de grafica publiquem dos articles avaluats segons l'avaluació científica; dos ressenyes i per primera vegada un article a la secció Expertia que signa el catedràtic emèrit de la Universitat Pompeu Fabra el dr. Jordi Pericot.

En l'Expertia que Jordi Pericot ha tingut l'amabilitat i complicitat d'oferir-nos, s'exposa un concepte innovador i alhora de reflexió: el disseny fruit de les interaccions i multi-interaccions entre els diferents agents que intervenen en el procés comunicatiu que representa l'ús de medis gràfics: el "disseny deliberatiu». La transformació tecnològica de la societat fa que el dissenyador tingui nous requisits? S'està creant un nou meta sector de suports i actors socials vinculats al disseny? Els canvis socials de producció i consum fan que aparegui el que Jordi Pericot denomina "disseny deliberatiu»? I en cas de ser així, quin perfil ha de tenir el dissenyador per treballar en aquest context de diàlegs?

Aquest preludi de qualitat, que ben segur ens farà pensar en quin ha de ser el futur del disseny i dels dissenyadors, el segueixen dos articles científics avaluats segons els criteris d'avaluació científica, objecte principal de la nostra activitat editora: 
El primer article d'investigació que presentem és "La dona al cartell polític i social del període 1931-1939» És un document que mostra la dualitat del disseny: per una banda podem analitzar els objectes de disseny des d'una perspectiva formal, observant com els estímuls formals son disposat en els espais gràfics; i per una altra, podem veure quin ha estat el seu ús des d'una visió més social. En aquest sentit, el treball presenta els resultats d'una recerca, finançada pel Centre d'Història Contemporània de Catalunya, on s'identifiquen diversos arquetips de representació de la dona. És una investigació acurada, realitzada amb rigor que aporta informació sobre la iconització de la dona en la propaganda del període estudiat.

El segon article d'investigació és “¿Imagen o texto? El poder de captar la atención visual de los elementos gráficos analizado con el Eye tracker». Es una interessant demostració de l'amplitud dels camps que miren als obejctes de disseny. Evidentment la percepció juga un paper important i des d'aquesta perspectiva, les aportacions des de la psicologia aplicada al disseny han estat sempre importants. Però també, la tecnologia com a factor de doble interacció. Per un costat ens ajuda a construir més objectes i millors; i alhora, ens permet estudiar millor la seva interacció amb els usuaris. L'article presenta els resultats d'una investigació que utilitzant la tecnologia Eye Tracking per estudiar els efectes de l'atenció visual en els anuncis gràfics publicitaris mostra la influencia dels estímuls gràfics en la comunicació.

Per acabar els continguts d'aquest número de la revista, dues ressenyes segueixen a aquests dos articles d'investigació. En primer lloc, la primera ressenya ens informa de la realització d'una Tesis doctoral que estudia el codi visual construït pels elements formals del missatge gràfic en els packs. Una segona ressenya ens explica una experiència docent que implica a la investigació científica en disseny gràfic i a la reflexió formativa dels estudiants respecte del disseny.

En començar aquesta editorial utilitzàvem la metàfora de l'espai de color per representar la construcció d'un espai científic útil per ser utilitzat pels diversos agents que intervenen en els processos de disseny, de manera general, i del disseny gràfic de manera molt específica. Acadèmics, Estudiosos i Investigadors socials i d'humanitats, han de poder trobar a grafica un espai prou confortable per ser utilitzat en el intercanvi d'idees i coneixements que portin al desenvolupament d'un àmbit, el del disseny gràfic, mancat de suficient reconeixement científic. Encara perdura la idea que el disseny i el dissenyat és difícilment abordable des del coneixement objectiu. Hi ha qui encara considera, pressuposa i prejutja que el disseny és un objecte 
d'estudi i de construcció de significats virtuós, depenent de qui el fa dependrà el seu valor; i virtual en tan que no perdurable i molt inconsistent. No ens interessa aquesta discussió i sí en canvi la de mostrar el coneixement que permet avançar en la construcció del que el disseny, com activitat professional i acadèmica reclama: un espai de coneixement on l'acumulació de sabers permeti construir nous i sòlids coneixements sobre l'objecte d'estudi que representa el disseny.

Definint el perfil del nostre objecte d'estudi!!! 


\section{\#EDITORIAL volumen 1.2}

El tema principal de esta editorial es escribir una nueva página del trayecto de la revista y del proyecto que representa grafica. Hemos titulado la editorial como «Espacio grafica» con la intencionalidad de hacer un símil con lo que representa el espacio color. De la misma manera que el espacio color queda definido por los colores periféricos que lo delimitan y los constituyen, el espacio grafica queda delimitado por las ideas que en el proyecto editorial de la revista queda reflejadas o consideradas. En este sentido, en los últimos meses desde la última edición hemos orientado la tarea de afirmación de la revista como medio para el mundo gráfico al ampliar las vinculaciones académicas y científicas que den solvencia al proyecto editorial. Esto ha permitido aumentar los miembros de las comisiones y de manera consecuente, aumentar los puntos de vista y las preocupaciones, que en este sentido, pueden ser referentes para grafica.

Una de las primeras preocupaciones e implicaciones que queremos poner a debate es ¿qué es la investigación en diseño gráfico? La pregunta puede parecer ingenua pero en el fondo no tiene nada de eso. Si en las primeras líneas argumentarías que dan sentido a la revista grafica eran las múltiples perspectivas que sobre esta actividad se tienen; es normal que la respuesta a la pregunta formulada pueda tener más de una respuesta. Ciertamente que la orientación de la revista está condicionada o auto condicionada voluntariamente, por los criterios de evaluación de revistas científicas. No obstante, no podemos menospreciar la reflexión conceptual que los estudiosos hacen a través de sus trabajos. Además, dado el interés de la revista por ser útil a los diversos agentes, científicos, académicos, estudiantes y profesionales hace obligado poder dar salida a las diversas necesidades y obligaciones que adquirimos.

Por esta razón, grafica salió por primera vez con un formato y secciones que permiten ser sensibles 
a cualquier perspectiva que sobre el diseño se quiera poner en común. La sección de Expertia para autores consagrados, que como expertos, puedan dar un punto de vista reflexivo y con mucha utilidad a quienes se encuentren a medio camino o iniciándolo. En este sentido, escuchas y saber escuchar lo que estudiosos que han realizado el camino antes que los demás, son capaces de explicarnos, nos debe dar la capacidad de adquirir una solvencia como ámbito de conocimiento que a menudo reclamamos y que no somos capaces de tener. Por otra parte, la sección de artículos de investigación, centro estratégico de la revista, debe ser el motor de divulgación científica y académica que nos permita evidenciar la hegemonía del diseño en muchas de las actividades sociales. A más artículos y más orientados a los cánones de referencia científica internacional más seguridad de que estaremos haciendo bien las cosas. Esto significará que tendremos un espacio, un espacio grafica, de referencia para estudiantes, profesionales, académicos y científicos, cuestión esta que nunca ha estado antes planteada con tanta profundidad y amplitud. En este sentido, a menudo, las revistas dedicadas al mundo gráfico y del diseño se han orientado más a cuestiones divulgativas, especulativas y de marcar de las tendencias formales. No es esta la idea editorial de grafica. Queremos estar al servicio de la construcción de un conocimiento sobre del cual se podrá seguir construyendo conocimiento científicoAsí pues, la sección de artículos es para grafica, la herramienta principal y única por la que grafica obtendrá la excelencia futura.

Pero no podemos hacer una revista únicamente con artículos científicos, al menos por ahora. Por eso, el Expertia, y por eso también, las reseñas. Esta sección he de dar salida a cualquier idea de aportación que no pueda entrar en los criterios, estrictos criterios científicos de grafica, que están alejados a los tradicionales criterios divulgativos de las revistas sobre diseño.

En las reseñas tienen cabida cualquier escrito que hable sobre diseño y desde las más amplias perspectivas posibles. Estudios de caso, Análisis críticos, Crónicas, Reportajes tienen cabida en la sección de reseñas, un espacio perfecto para desarrollar sus pensamientos. Especialmente esta sección ha sido pensada para hacer notas de prensa o breves descripciones de trabajos científicos, trabajos de final de grado o máster, o de cualquier trabajo que los estudiantes hayan podido realizar en sus estudios y que tengan un cierto interés en compartirlos. A menudo, estos trabajos quedan publicados en revistas que el tiempo las convierten en caducas. El hecho que grafica sea editada online hace que pueda ser indizada, 
referenciada y encontrada en la red para siempre. A parte del interés de los autores, aquí también queremos mostrar el interés por la comunidad dado que a menudo no se conoce lo que hacen estudiosos del tema sean éstos próximos o lejanos.

Así pues, queremos hacer partícipes a los lectores que saben lo que buscamos y saben las dificultades que tenemos por delante pero también son conscientes de los motivos que nos impulsan. Las dificultades iniciales que toda publicación como grafica tiene las convertimos en motivos esenciales para seguir trabajando; de la necesidad de encontrar el tono científico y la utilidad requerida para grafica, hacemos objetivos a conseguir; de la necesidad de implicar a los estudiosos de todo el mundo, y en especial de Latinoamérica, hacemos la estrategia que nos debe dar solvencia: y finalmente, de la obligación de ser un servicio para los públicos interesados en el diseño gráfico, hacemos la razón de nuestra existencia. Si a estas ideas añadimos la necesidad de conseguir, en un tiempo razonable, la indexación de grafica como revista científica, encontraremos la explicación al trabajo que estamos realizando.

Trabajo por tanto, que se puede visualizar en la construcción de un espacio grafica donde todos debe tener cabida y un espacio donde todos deben sentir como propio y referencial. Tanto el Col-legi Oficial de Disseny Gràfic de Catalunya como agente emulsionante, como las Escuelas de diseño, Universidades, profesionales y académicos, de ámbitos lingüísticos distintos, son invitados a motivar, impulsar y difundir el uso de grafica como referente para el desarrollo de grafica.

En el caso de la segunda edición de grafica publicamos dos artículos evaluados según la evaluación científica; dos reseñas y por primera vez un artículo en la sección Expertia que firma el catedrático emérito de la Universitat Pompeu Fabra el dr. Jordi Pericot.

En el Expertia que Jordi Pericot ha tenido la amabilidad y complicidad de ofrecernos, se expone un concepto innovador y a la vez de reflexión: el diseño fruto de las interacciones y múlti-intercacciones entre los diferentes agentes que intervienen en el proceso comunicativo que representa el uso de los medios gráficos: el «diseño deliberativo». ¿La transformación tecnológica de la sociedad hace que el diseñador tenga nuevos requisitos? ¿Se está creando un nuevo meta sector de soportes y actores sociales vincu- 
lados al diseño? ¿Los cambios sociales de la producción y consumo hacen que aparezca lo que Jordi Pericot denomina «diseño deliberativo»? Y en el caso de ser así, ¿qué perfil debe tener el diseñador para trabajar en este contexto de diálogos?

A este prelidio de calidad, que bien seguro nos hará pensar en cual debe ser el futuro de diseño y del diseñador, le siguen dos artículos científicos evaluados con los criterios de evaluación científica, objeto principal de nuestra actividad editora:

El primer artículo de investigación que presentamos es «La dona al cartell polític i social del període 1931-1939» És un documento que muestra la dualidad del diseño: por una parte podemos analizar los objetos de diseño des de la perspectiva formal, observando cómo los estímulos formales son dispuestos en los espacios gráficos; y por otra, podemos ver cuál ha sido su uso desde una visión más social. En este sentido, el trabajo presenta los resultados de una investigación, financiada por el Centre d'Història Contemporània de Catalunya, donde se identifican diversos arquetipos de representación de la mujer. Es una investigación bien realizada, Es una investigación elaborada cuidadosamente y realizada con rigor que aporta información sobre la iconicidad de la mujer en la propaganda del periodo estudiado.

El segundo artículo de investigación es «¿Imagen o texto? El poder de captar la atención visual de los elementos gráficos analizado con el Eye tracker». Es una interesante demostración de la amplitud de los campos que miran a los objetos de diseño. Evidentemente la percepción juega un papel importante des de esta perspectiva, las aportaciones desde la psicología aplicada al diseño han estado siempre importantes. Pero también, la tecnología como factor de doble interacción. Por un lado nos ayuda a construir más objetos y mejores; y a la vez, nos permite estudiar mejor su interacción con los usuarios. El artículo presenta los resultados de una investigación que utilizando la tecnología Eye Tracking para estudiar los efectos de la atención visual en los anuncios gráficos publicitarios, muestra la influencia de los estímulos gráficos en la comunicación.

Para acabar los contenidos de este número de la revista, dos reseñas siguen a estos dos artículos de investigación. En primer lugar, la primera reseña nos informa de la realización de una Tesis doctoral que estudia el código visual construido por los elementos formales del mensaje gráfico en los packs. Una 
segunda reseña nos explica una experiencia docente que implica a la investigación científica en diseño y a la reflexión formativa de los estudiantes respecto del diseño.

Al empezar esta editorial utilizábamos la metáfora del espacio de color para representar la construcción de un espacio científico útil para ser utilizado por los diversos agentes que intervienen en los procesos de diseño, de manera general, y de diseño gráfico de manera muy específica. Académicos, Estudiosos e Investigadores sociales y de humanidades, han de poder encontrar en grafica un espacio suficientemente confortable para ser utilizado en el intercambio de ideas y conocimientos que lleven al desarrollo de un ámbito, el del diseño gráfico, falto del suficiente reconocimiento científico. Todavía perdura la idea que el diseño y lo diseñado es difícilmente abordable desde el conocimiento objetivo. Hay quien todavía considera, presupone y prejuzga que el diseño es un objeto de estudio y de construcción de significados virtuoso, dependiente de quien lo haga dependerá su valor; y virtual en tanto que no perdurable y muy inconsistente. No nos interesa esta discusión y sí en cambio la de mostrar el conocimiento que permite avanzar en la construcción de lo qu el diseño, como actividad profesional y académica reclama: un espacio de conocimiento donde la acumulación de saberes permita construir nuevos y sólidos conocimientos sobre el objeto de estudio que representa el diseño

Definiendo el perfil de nuestro objeto de estudio!!! 